\section{The precautionary principle and epidemiology: a contradictio in terminis?}

\section{A Tukker}

\section{By its nature, epidemiological science has only a limited ability to judge the need for preventative action, which is a core element of the precautionary principle}

7 he precautionary principle is gaining more and more ground as a guideline in environmental policy. Quantitative risk assessment no longer seems sufficient. In point of fact, historical analysis of several debates showed me that different societal groups structurally use different "paradigms", "world views", or "frames" to evaluate threats of man-made substances. ${ }^{12}$ Briefly, the two most contrasting views are*:

- Adherents of what I termed the risk assessment frame believe that knowledge is adequate, that emission control will work, and that nature is quite resilient. Hence, they fully accept a management model where emissioneffect calculations are used to assess a possible danger, and in which emission reductions are an adequate response to avoid exceeding a danger threshold (see for example, CEFIC ${ }^{3}$ ).

- Adherents of the precautionary frame dispute that there is sufficient knowledge to be able to rely on this approach in the first place. Hence, they judge substances primarily on indicators reflecting factors like their inherent safety, the possibility that we are ignorant of possible effects, and the reversibility of contamination (which would allow wrong judgements to be corrected). Materials that can be produced safely without complex emission control, and for which waste management is easy, have their preference (see for example, Chemicals Policy Committee ${ }^{4}$, Stringer and colleagues ${ }^{5}$, and Thornton ${ }^{6}$ ).

Unfortunately, the debate between these groups often develops into a "dialogue of the deaf". Parties on both sides simply caricature each other's position: precaution would lead to a standstill of all innovation, it is claimed, and risk assessment neglects ignorance. This really is a pity as risk assessment and precaution are not mutually exclusive. The precautionary principle merely seeks to properly include ignorance and uncertainty in decision making, and good science, including good risk assessment, tries to do the samet. The question therefore is how to balance the need to take ignorance into account without falling into the trap of demanding for (an impossible) policy option that rules out all ignorance and uncertainty. Below, I will discuss to what extent epidemiology can be of help in finding this balance. For this purpose, a closer look at precaution is necessary first.

The Rio Declaration of 1992 marked the broad acceptance of the precautionary principle in environmental policy. ${ }^{8}$ Regardless of the definition used, as a minimum the following elements form key aspects of the principle. ${ }^{9-12}$ See footnoteキ:

l safeguarding ecological space: the margins of tolerance that nature allows for contamination should not even be approached. ${ }^{12}$ This implies a shift of focus away from the so called assimilative capacity approach in environmental policy-that is, policies based on "'dilute and disperse" $\mathrm{e}^{\prime 11}$,

2 preventive anticipation: a willingness to take action in advance of scientific proof or final evidence ${ }^{1012}$

3 proportionality of response or cost effectiveness in relation to margins of error;

4 reversal of the burden of proof: this burden should be placed on those who propose change (less relevant for this article).

Obviously, epidemiology is a very useful form of science. Through epidemiological research it is possible to link possible causes with effects, which can provide a better understanding of these

*There is also an intermediate "strict control" precautionary strict control measures (compared frame that deals with ignorance by imposing with preventive phase out). relations. In principle, this might help to make a judgement on points (1) and (3) above. However, in relation to point (2) one has to acknowledge that epidemiology has a number of fundamental problems if the purpose is to use it as a means of reconciling the discussion on precaution. One of these problems is pragmatic, and two of them are fundamental.

The first, pragmatic problem is that epidemiological studies are very hard to conduct and do not always produce conclusive evidence about cause-effect relations. Particularly when the effects are comparatively weak, or only become apparent after a long incubation period, there is usually considerable and protracted debate among epidemiologists before a particular risk factor is generally acknowledged as such-if indeed the discussion does reach a conclusion. The question of whether or not male sperm counts are declining is still open to debate, let alone whether this arguable effect can be linked to a particular cause. Even for exposure to asbestos and cigarette smoke it took years, if not decades, before there was general acceptance of the fact that it did indeed increase cancer risks. In fact, David Ozonoff, head of the respected Environmental Health Section of Boston University, once made the statement that "A good working definition of a catastrophe is an effect so large that even an epidemiological study can detect it" (page 254). ${ }^{13}$ Taken out of context this statement probably does not do justice to epidemiological science, but it clearly touches on a problem for those who want to give epidemiology a prominent role in a debate on the need to take preventive action.

The second and third problems are more fundamental. Firstly, by its nature epidemiology looks back in time. Given

†Although one can express reservations about risk assessment in its present form. By 1998 at least four studies had shown that even for the 3000 high production volume chemicals (let alone the tens of thousands of other man-made chemicals) the basic data for the Screening Information Data Set were publicly available in only $10 \%$ of cases. This, of course, is at odds with the impression that is often given that a risk assessment is based on "hard facts".

$\ddagger \mathrm{O}^{\prime}$ Riordan and Cameron (page 18) ${ }^{12}$ also mention the promotion of the cause of intrinsic natural rights (that is, an ethical point) and paying for past ecological debt (known heavy polluters should take more precautions than others). The Wingspread version of the principle is one of the few that poses demands on the decision making process like openness, inclusion of affected parties, and examination of alternatives. 
the diets, exposures, and lifestyles, etc, during a population's life to date, already detectable effects might be linked to certain causes. This, of course, is hardly an attractive proposition for a supporter of the precautionary principle, who wants to avoid the occurrence of effects by looking forward and taking preventive action. Secondly, epidemiology needs to identify an exposed target group and a non-exposed control group. As has been stated, perhaps most eloquently by Thornton, ${ }^{6}$ most of the exposure of humans to chemicals, persistent chemicals in particular, is indirect. Over a 100 persistent chemicals at least can be found in human body tissue, regardless of whether the person lives in an industrialised country or a remote region, like the Inuit in northern Canada. For such chemicals, no unexposed control group can be found anymore. Therefore, epidemiological studies will be blind to the probability that such chemicals might be the cause of detected effects, as exposure cannot be a discriminating factor anymore and thus not identified as a cause.

What does this all mean? In my view, there is no way of avoiding the conclusion that epidemiological science in the traditional sense is of little help in debates centred around precaution. The three arguments above, particularly when taken in combination, make clear that by its nature epidemiology fails to tackle a core element of the principlethat is, how to judge the need for preventive action. Epidemiological evidence of danger can normally only be given after years, if not decades, of exposure of large groups of subjects-by which time we could well find ourselves in a situation that the precautionary principle actually wants to avoid. The past exposure may still lead to unacceptable and non-preventable effects in future (for example, DES and asbestos). Contamination may have been irreversible so that exposure will only slowly diminish (for example, dioxins). Or an industrial infrastructure may have been created in the mean time that can only be converted at excessive cost (for example, certain parts of the chlorine industry like CFC production). And by then, the owners of that infrastructure are in a position where they will only accept extremely convincing evidence of danger, which will delay preventive action even further (for example, cigarette producers).

So how then should we deal with a discussion on precautionary action? This is a subject for a paper in itself (see references ${ }^{2}$ ), but I believe a few guidelines can be given.

Firstly, one should make a clear distinction between (new) activities that lead to irreversible situations (infrastructure, exposure, contamination) and those that do not. Reversible situations are much less critical as they allow for learning by doing; irreversible situations are much more critical.

Secondly, one should somehow classify (new) activities according to the potential uncertainty and ignorance with regard to their effects. An extreme example: a chemical process that emits only substances that already occur naturally scores much lower on the "ignorance" scale than a plant that starts to produce a novel, purely man-made chemical.

Supporters of the precautionary principle will be extremely hesitant to accept a new activity that will create an irreversible situation and for which uncertainty and ignorance about its effects are likely to be high (for example, nuclear power creating nuclear waste). The only solution here is to "try out" the new activity under very controlled, small scale (and hence reversible) conditions and then learn whether the ignorance is indeed as great as feared. Here there might be a role for epidemiology, but then in the form of a "monitoring tool" in this "laboratory-like" testing situation (though we can hardly call this epidemiology in a traditional sense anymore). And finally, one should maybe accept that in a way there will always be a debate between people who want to innovate quickly at all costs and those who want to think about the consequences first. Indeed, some policy scientists argue that this is a debate for all places and for all times, and that this continuous debate rather than its resolution is essential for balanced human progress. ${ }^{14}$

$J$ Epidemiol Community Health 2002;56:883-884

\section{Author's affiliations}

A Tukker, TNO Institute of Strategy, Technology and Policy, Postbus 6030, 2600 JA Delft, the Netherlands

Correspondence to: Dr A Tukker; Tukker@stb.tno.nl

\section{REFERENCES}

1 Tukker A. Frames in the toxicity controversy. Risk assessment and policy analysis related to the Dutch chlorine debate and the Swedish PVC debate. Dordrecht: Kluwer Academic, 1999.

2 Tukker A. Risk analysis, life cycle assessment-the common challenge of dealing with the precautionary frame. Risk Analysis 2002;22:819-30.

3 CEFIC. Comments on the draft declaration of the 4th North Sea conference, 9 January 1995. Brussels: CEFIC, 1995.

4 Chemicals Policy Committee. En Hållbar Kemikaliepolitik. Riskpanorama för kemikalier. [With a summary in English.] Stockholm: Offentliga Publilationer, SOU 1997:84 Fritzes.

5 Stringer RL, Johnston PA, Clayton R, et 1 . Back to the basics: The case for an intensification in the monitoring of point source discharges. Submitted by Greenpeace International to the 19th Meeting of the Joint Monitoring Group of the Oslo and Paris Commisions. Exeter: Greenpeace Exeter Research Laboratory, 1994.

6 Thornton J. Pandora's poison: chlorine, health, and a new environmental strategy. Cambridge, US: MIT Press, 2000.

7 Stirling A, ed. On Science and Precaution In the Management of Technological Risk. An ESTO Project Report. EUR 19056 EN. European Commission - JRC/IPTS, Seville: European Commission, 1999. (www.jrc.es)

8 United Nations Conference on Environment and Development. Rio Declaration on Environment and Development. 31 ILM 874. New York: United Nations Press 992

9 Attfield R. The precautionary principle and moral values. In: O'Riordan T, Cameron J. Interpreting the precautionary principle. London: Earthscan Publications, 1994:152. publisher

10 EU. Communication from the Commission on the precautionary principle Brussels. 2.2.2000, COM(2000) 1 final. (http://europa.eu.int/eur-lex/en/com/cnc/ 2000/com2000_0001 en01.pdf).

11 Freestone D, Hey E. The precautionary principle and international law, the challenge of implementation. The Hague: Kluwer Law International, 1996

12 O'Riordan T, Cameron J. The history and contemporarty significance of the precautionary principle. In: O'Riordan T, Cameron J. Interpreting the precautionary principle. London: Earthscan Publications, 1994.

13 Wildavsky A. But is it true? A citizens guide to environmental health and safety issues. Cambridge, US: Harvard University Press, 1995.

14 Thompson M, Ellis R, Wildavsky A. Cultural theory. Boulder, CO: Westview, 1990. 